\title{
Cross Curricular Science in Elementary Schools in Greece - The Curriculum Factor
}

\author{
Konstantinos Karampelas \\ Pedagogic Department of Education, \\ University of the Aegean, \\ Rhodes, Greece
}

\begin{abstract}
This paper examines the opportunities provided for the integration of science activities in the teaching packages of elementary school subjects in Greece. Research has shown that integrating tasks in teaching science can offer a holistic teaching approach. Various suggestions to integrate science with other subjects have been proposed as a means to promote scientific literacy. This can be assisted by an appropriate teaching package. Based on this assertion, this research was designed to highlight cross-curricular science possibilities that curricula and teaching packages in other subjects can offer. A qualitative contentanalysis approach led to the conclusion that there are certain opportunities for integration.
\end{abstract}

Keywords: integration, curricula, teaching packages, science, elementary school.

\section{Introduction}

The main theme of this paper is integration. This concept has attracted the attention of theorists over the last few decades. There are multiple approaches towards integration, mainly in terms of usability and implementation as a combination of different subjects in teaching. Jacobs (1989) describes integration as a conscious and deliberate approach to construct knowledge, develop skills, and promote attitudes from different learning fields based on a topic, a question, or a challenge. However, many other definitions have been given on that basis. Davison, Miller, and Metheny (1995) consider that this variety might cause confusion to educators and repel them from implementing integrating and cross-curricular activities as a teaching practice despite its' justified benefits. The stated definitions have commonalities. Any differentiation might be attributed to the context within which integrating activities are implemented each time. In the light of the specific research, which focuses on the teaching of science, it is necessary to take into consideration the main points of science education. theory and practice. It is also necessary to take into account the context of education 
being addressed, which is the elementary level of the Greek education system (Lonning \& DeFranco, 1997).

Generally, there is research around integrating science with other subjects, individually (Harlen \& Qualter, 2009; Jarvis, 2009). This research, however, is an effort to go beyond examining this individual level and examine opportunities for integration in the whole elementary education curriculum, in a specific context.

Within this scope, this project focuses on aiming to find out what opportunities exist for teachers to integrate science at the six grades of elementary school in Greece in terms of curricula and teaching packages. This calls for precision in examining the basic points of teaching science in the particular context through the prism of curricula and teaching packages as means of instruction (Pang \& Good, 2000).

\section{The Context of the Study}

The Greek educational system has been identified by Organization for Economic Cooperation and Development, OECD (2017) to be highly centralized. Several decisions and issues concerning school functioning are determined by the Ministry of Education. An example of the centralized character of the system is the fact that teachers are expected to use pre-designed teaching packages in all subjects that are taught. These packages include teachers' books with predesigned lesson plans as well as learners' books and workbooks, all of which are distributed to schools.

Table 1: Subjects Taught in Elementary Schools in Greece and Weekly Sessions per Unit. The ones in Italics are not taught by mainstream teachers. The numbers may not apply to multi-grade schools (MINEDU, 2018)

\begin{tabular}{|l|c|c|c|c|c|c|}
\hline Subject & $\begin{array}{c}\mathbf{1}^{\text {st }} \\
\text { grade }\end{array}$ & $\begin{array}{c}\mathbf{2}^{\text {nd }} \\
\text { grade }\end{array}$ & $\begin{array}{c}3^{\text {rd }} \\
\text { grade }\end{array}$ & $\begin{array}{c}\mathbf{4}^{\text {th }} \\
\text { grade }\end{array}$ & $\begin{array}{c}5^{\text {th }} \\
\text { grade }\end{array}$ & $\begin{array}{c}\mathbf{6}^{\text {th }} \\
\text { grade }\end{array}$ \\
\hline Religion & - & - & 2 & 2 & 1 & 1 \\
\hline Greek & 9 & 9 & 8 & 8 & 7 & 7 \\
\hline Mathematics & 5 & 5 & 4 & 4 & 4 & 4 \\
\hline History & - & - & 2 & 2 & 2 & 2 \\
\hline Environmental study & 4 & 4 & 2 & 2 & - & - \\
\hline Geography & - & - & - & - & 2 & 2 \\
\hline Science & - & - & - & - & 3 & 3 \\
\hline Politics-social studies & - & - & - & - & 1 & 1 \\
\hline Flexible zone & 3 & 3 & 2 & 2 & - & - \\
\hline Arts & 2 & 2 & 1 & 1 & 1 & 1 \\
\hline Music & 1 & 1 & 1 & 1 & 1 & 1 \\
\hline Drama & 1 & 1 & 1 & 1 & - & - \\
\hline Physical education & 3 & 3 & 3 & 3 & 2 & 2 \\
\hline English & 1 & 1 & 3 & 3 & 3 & 3 \\
\hline French/German & - & - & - & - & 2 & 2 \\
\hline ICT & 1 & 1 & 1 & 1 & 1 & 1 \\
\hline Total sessions per week & 30 & 30 & 30 & 30 & 30 & 30 \\
\hline
\end{tabular}


In Greece, the elementary school addresses children between the ages of six to 12 years old. It is completed in six different grades, 1-6. Children of the same age go to the same grade. The teachers may differ with regards to specializations and teaching qualifications. All grades have language, mathematics, English, ICT, physical education, arts, and music classes. From grade 3 onwards, religion and history are introduced as subjects.

In grades 1-4, there are drama, flexible zone, and environmental studies classes. Flexible zone has no specified area of focus. Within this subject, teachers are expected to design their own projects mainly by integrating subjects. Environmental studies is a cross-curricular subject including topics from science, geography, and political-social issues.

In grades 5-6, all these subjects are no longer taught. However, new subjects are introduced. Instead of the unified environmental study, there are autonomous subjects of science, geography, and politics. Additionally, a new foreign language, either French or German, is also taught, (MINEDU, 2018).

Mainstream elementary school teachers teach the majority of subjects, while specialized teachers teach subjects such as English, French, German, arts, music, drama, physical education, and ICT. Lastly, there may also be special education teachers for learners with special needs and learning difficulties (MINEDU, 2018).

\section{Integrating Activities in Teaching}

According to Banks (1993), integration is relevant to the level that educators take advantage of cases, data, or information from different subjects or research fields in order to construct concepts, theories, and teaching goals within their work. Its importance can be placed on three different levels where it can be applied.

The first is discipline specific level. This can assist learners in conceiving the complexity of teaching subjects. An example can be environmental topics that are linked with different subjects, all of which are considered important. Such topics may be approached as challenges, problems to be solved, without clear precise solutions and call for decision-making.

The second is content specific integration. This has similar benefits and assists learners in understanding how a topic, concept, and phenomenon from one subject can be implemented in or be important to others. An example is measurement units and counting in general that can be used in more than one subject, such as mathematics, science, and geography (Davison et al., 1995).

Lastly, there is methodology-specific integration, which is also process specific, and relates to practices, skills, and procedures that may involve observation, critical thinking, stating findings, and constructing knowledge. Problem solving might be considered as a common example, especially when based on a theme or context that touches many areas of study (Trisdiono et al, 2019; Sirih et al, 2019).

In short, integration helps teachers in dealing with knowledge fragmentation, which is a result of teaching only subject with robust, concrete borders between them and no possibility for interaction. By dealing with it, integration can 
provide a more realistic and complete approach to topics and teaching (Davison et al., 1995; Akerson \& Flannigan, 2000; Elstad et al, 2019).

The effective implementation of integration in teaching, however, requires the appropriate curriculum, which is directly linked to the quality and outcome of teaching and learning. Teaching approaches used in the classroom are influenced by the curriculum that educators are expected to follow (Hargreaves, 1991). Loepp (1999) adds that curriculum can assist in turning the theory supporting integration into action by stimulating teachers' interest in integration and can provide ideas, suggestions, information, and helpful guidance on activities, tasks, and units that may combine elements of different disciplines.

\section{Integrating Activities in Science}

In examining the topics of integration in science, it is important to consider the main points of integration of subjects from a general perspective and then focus on each of them specifically.

\section{Approaching Cross-Curricular Science}

The implementation of integration in science needs to take the particular characteristics of the subject into thorough consideration (Lonning \& DeFranco, 1997). A basis for designing and planning integrating activities in science is to achieve scientific literacy. According to $\operatorname{OECD}(2017$, p. 17) scientific literacy is defined as follows:

"the ability to engage with science-related issues, and with the ideas of science, as a reflective. citizen. A scientifically literate person is willing to engage in reasoned discourse about science and technology, which requires the competencies to: explain phenomena scientifically - recognise, offer and evaluate explanations for a range of natural and technological phenomena; evaluate and design scientific enquiry - describe and appraise scientific investigations and propose ways of addressing questions scientifically; interpret data and evidence scientifically - analyse and evaluate data, claims and arguments in a variety of representations and draw appropriate scientific conclusions."

Integration can be very useful in approaching and achieving scientific literacy. The reason is that elements of scientific literacy can be promoted or implemented in disciplines other than science. An integrating approach may help learners get a more realistic view of topics and issues in science (Hodson, 2008; Harlen \& Qualter, 2009).

Integration in science can be achieved in three levels. The first is the level of concepts and knowledge. Such integration is done with the help of activities that negotiate concepts which are part of science as well as other subjects. The second is the level of activities. Lastly, the third is the level of practices. Certainly, the borderline between these levels is not always precise (Davison et al, 1995). 


\section{Implementation of Integrating Activities in Science}

Designing and implementing integrating activities in science is a complex task. This is probably the reason educators are challenged to apply and include such activities in their teaching work (Hodson, 2008; Harlen \& Qualter, 2009). A crucial condition is the appropriate preparation of educators around the theory, necessity, management, implementation, and evaluation of integration. A second basic condition is the support and promotion from the curriculum and the school where educators work. Lastly, the third condition to have the appropriate material.

These three conditions can be satisfied with the assistance of the appropriate teaching package for educators, which could include theoretical and practical preparation material and promote integrating projects. In this context, Gresnigt (2018) stresses the importance of the relationship between integration and goals while analyzing different levels of integration. In fact, there is a level where a teaching unit or task may be focused on a single goal, which may fit more than one discipline. However, in other levels, there may be complex activities that are mostly inquiry-based in which integration helps in approaching the subject in a real-life context. An appropriate curriculum can clarify these goals.

However, it has been justified by Hodson (1992) as well as Cervetti, Pearson, Barber, Hiebert and Bravo (2007) that there are cases where curricula and teaching packages are not totally compatible in solving issues around teaching approaches and practices including integration.

\section{Science and Other Subjects}

A variety of integrating science activities have been described in research. These include combining science with almost all known subjects. There have been suggestions for integrating science with language, mathematics, arts and ICT (Harlen \& Qualter, 2009; Jarvis, 2009). The focus of the study will be on the integration of science with the subjects of Greek elementary school that are, by law, the responsibility of mainstream elementary teachers; these subjects include language, mathematics, geography, history, religion, and social studies (MINEDU, 2018).

\section{Science and Language}

There are plenty of features that can link the subjects of language and science as mentioned in research. Initially, the level of concepts is by default a common feature between the subjects as concepts and vocabulary of science and any field are relevant to language. At the level of processes and skills, common features may be the analysis of data and information, formation and statement of explanations and conclusions as well as the general dialogue, interaction and discourse (Akerson \& Flanigan, 2000).

It is generally justified that integrating activities are compatible with inquiry tasks that focus on everyday life conditions and aim to construct knowledge along with skills, practices, and attitudes. The main reason is that it is an 
opportunity to approach a topic authentically by taking into consideration all parameters and subjects involved (French, 2004).

\section{Science and Mathematics}

The common features between science and mathematics as stated in literature and curricula are linked to concepts, skills, and practices. At the level of concepts, there are vast areas common to science and mathematics, such as measurement units. There is also the relationship between concepts and factors. At the level of skills, problem solving, and using data for experimentation and explanation are widely accepted common features. Lastly, at the level of attitudes, there is the desired attitude to quantify and appreciate the quantification of states and concepts along with the linkage to everyday life experiences (Davison et al., 1995; Lonning \& DeFranco, 1997; Pang \& Good, 2000).

As with language, inquiry and project-based learning is usually preferred and considered to be more fruitful in terms of integration with science, contrary to traditional direct instruction of defined specific subjects (French, 2004).

\section{Science and History}

Even though there has been research on how to implement the integration of science and history, this research is not as widespread as it is with language and mathematics. Whenever a project is planned to integrate history and subjects such as science and mathematics, it usually aims to emphasize on the importance of scientific discoveries in history and the development of humankind. This involves observing and understanding the importance of scientific progress in important social reforms and changes. This, in turn, can help pupils appreciate the general interaction between science and society. In fact, in some textbooks, there are historical notes at the end of chapters that are supposed to be used as further reading sources to stimulate the interest of pupils towards the subject. However, little evidence is there to support its effectiveness (Fauvel \& Maanen, 2005; Masson \& Vasquez-Abad, 2006).

However, history is justified in assisting in the promotion of the fairly new and innovative aspects of science teaching. Such is the nature and philosophy of science, which is being recognized as an important dimensions of science teaching, that has been neglected in favor of content knowledge. By examining the history of science, it is possible for learners to see how science developed and construct basic knowledge around science and its characteristics, such as for example, the fact that scientific knowledge might change, be rejected, or be enriched in the light of new evidence. In this manner, learners can also understand the importance of experimentation and inquiry in science (Abd-ElKhalick, Bell, \& Lederman, 1998; Akerson \& Hanuscin, 2007; Hascunin, Lee, \& Akerson, 2011; NGSS Lead States, 2013).

\section{Science and Religion}

As with history, the theory and ideas about integrating science with religion seem to be rather limited as compared to other subjects. This can be attributed to 
the view that these two subjects are contrasting in some ways, however, there are other views that approach the two subjects as parallel or interlinked and supportive (Barbour, 2000). Hanley, Bennett, and Ratcliffe (2013) believe that it may be up to teachers, the curriculum and teaching to make sure that learners reject misconceptions about the controversy between science and religion through integrating activities. However, there is a concern when teaching specific topics such as evolution.

However, Gauld (2005) insists that these topics should not be omitted from teaching in order to familiarize learners with ways to deal with them and overcome any, possibly unjustified, dilemmas or debates. Additionally, he claims that science and religion should be integrated on the basis of habits, skills, such as critical thinking, and inquiry-based activities. In combination with that guideline, Jegede and Aikenhead (1999) suggest that teaching culturally oriented subjects, such as religion, can have benefits by incorporating science-like projects and inquiry methods through the scope of problem solving. This could include engaging learners in tasks where they have to use scientific methods and data to develop attitudes and take decisions that concern human rights, racism, or environmental issues. These topics that can be identified in the curriculum of subjects, such as religion, can be dealt with using an appropriate integration with scientific topics. The curricula and teaching packages should thus follow this approach.

\section{Science and Geography}

Geography itself is approached by theorists as an interdisciplinary area of study by default. Therefore, there are plenty of opportunities to combine it with other subjects including science. Schaefer (1953) approaches geography as a linking subject between science, economy, and social studies. Baerwald (2010) sums up that geography generally deals with topics such as regional analysis, spatial analysis as well as interactions between humans and the environment, climate, and flora and fauna. These are topics that can be linked to science subjects. Considering all these factors, Lisowski (2011) supports the claim that perhaps the teaching of geography can be a good opportunity for the integration of science subjects because it allows for a more holistic and realistic approach to them as it incorporates and approaches the topics through different fields of study.

There are specific geography projects that supposedly enhance the opportunities for integration. This is because these projects are based on the development of skills and attitudes such as hypothesizing, observation, and critical thinking. Contexts such as "deforestation and ecological disasters", "natural disasters and policies required", "impact of tourists or industrial development on the natural environment", or "the influence of the landscape of one country on its' economic activities" can trigger discourse around topics that engage both science and geography ideas. (Drake \& Reid, 2018) stress that along with inquiry, in geography curricula, these topics are described as activities that lead to the generalization of ideas, evaluation of processes, and reflective thinking. These can be related to the implementation and application of scientific ideas in 
everyday life, which is a crucial part of science teaching (NGSS Lead States, 2013; Gresnigt, 2018).

\section{Science and Social Studies}

The integration of social studies and science has triggered the attention and interest of researchers. The features of this integration usually relate to history, geography and religion and are usually grouped into two categories: The first category is relevant to approaching social issues with a scientific perspective. It can be of value to equality and confrontation of racism as it is historically relevant to genetics and science as well as the link between science and social, political, and economic matters. In the latter context, there can be activities linking the types of jobs and occupations that citizens have in a community and scientific development. For example, there may be activities justifying findings such as the fact that industrialized societies may have a large numbers of factory employees (Lemke, 2001).

The second category addresses the social perspective of scientific work and how it is accomplished. Social subjects can teach lessons such as the freedom of speech, exchange of ideas as well as research and its implications on scientific progress. In addition, in social subjects, pupils can learn values such as respect, ethics, the importance of group work, cooperation, discourse, acceptance of innovative ideas, and the need to contribute to the development of humans (Lemke, 2001; Gresch \& Martens, 2019). These are all important values and skills in science as well (NGSS Lead States, 2013).

\section{Methodology}

This study was planned with the aim of highlighting the potential of teaching packages in promoting integrating activities combining science with other subjects in elementary schools in Greece. In order to achieve this aim, the teaching packages of the particular subjects were examined in terms of the three levels of integrating activities as defined by Davison et al. (1995): knowledge, activities, and practices. Therefore, the research questions were formed as follows:

1. Are there units in other subjects that are relevant to science?

2. Are there activities relevant to science?

3. Are there practices promoted in those subjects that are common with science?

The study is qualitative in nature (Cohen, Manion, \& Morrison, 2013) with data derived from text analysis. A total of 92 documents were examined. Among them, six were the curricula of the subjects: language, mathematics, history, geography, religion and politics. The rest were teachers' books, pupils' books and workbooks of these subjects (Jacobs, 1989; Pang \& Good, 2000; MINEDU, 2018). Codes are defined in the beginning as it is a common practice within qualitative research. These codes are keywords and concepts that are relevant to the sub-themes and parameters of the general topic. The codes are decided based on the basic theory and research findings of the topic under study. These codes are grouped into nodes, as shown on table 2. In this specific study, nodes 
are "units", "activities", and "practices" that match with each of the three respective research questions. Codes for the first research question under the node "units" could be "concepts" or "phenomena" of science as identified in chapters or units. Codes for the second research question under the node "activities" could be "topics" or "issues" relevant to science that were identified in tasks, questions, or activities. Lastly, codes for the third research question under the node "practices" could be "competencies" or "skills" such as critical thinking, observation, and data searching.

Table 2: Research Questions, Nodes and Codes

\begin{tabular}{|l|c|c|}
\hline Research Question & Nodes & Codes \\
\hline $\begin{array}{l}\text { 1) Are there units in other subjects that are } \\
\text { relevant to science? }\end{array}$ & Units & $\begin{array}{c}\text { Concepts, } \\
\text { phenomena }\end{array}$ \\
\hline 2) Are there activities relevant to science? & Activities & Topics, issues \\
\hline $\begin{array}{l}\text { 3) Are there practices promoted in those } \\
\text { subjects that are common with science? }\end{array}$ & Practices & $\begin{array}{c}\text { Competencies, } \\
\text { skills }\end{array}$ \\
\hline
\end{tabular}

After defining the nodes and codes, the texts are studied and coded. This means that extracts, words, phrases, or paragraphs of the texts that relate to one or more codes are identified. These are then gathered, counted, and analyzed. By comparing and commenting on the codes as found in curricula or teaching packages, the research questions are answered (Hodson, 1992; 2008; Cervetti et al., 2007; Cohen et al., 2013).

\section{Findings}

Findings in all three research questions show that the curricula of elementary subjects offer various opportunities for integration with science.

\section{Research Question 1}

In the first research question, as seen in Figure 1, the codes relevant to the concepts and units are frequently located in the curriculum and the teaching packages. More specifically, both the language and mathematics curriculum make references to "new literacies", pointing to scientific literacy as well (OECD, 2017). At the same time, there are references to the analysis of different texts, such as parts of weather forecasts and "scientific texts", while there are suggestions for cross-curricular activities involving "nature and environment" and "health and nutrition". The teaching packages of language include tasks about the "weather", "animals and seasons" and "the natural environment ecosystems". These are all opportunities for the introduction of integrating activities that combine language with science (Cervetti et al., 2007).

Simultaneously, in the mathematics curriculum, there is the general promotion of the idea of cross-curricular tasks. This is the case in the teaching packages as well. Teaching units include concepts such as length, volume, space, weight and mass, time, and measurements units. These are included in science as well and can serve as opportunities for integration (Lonning \& DeFranco, 1997).

The history curriculum also stresses the importance of integration with other subjects, including science though the combination science concepts and 
phenomena in history is limited. In the teachers' books, there are references to combining history with science motivated by facts such as the naming of planets after ancient Greek gods. Aside from that, the only apparent linkage with science is in units that may refer to the influence of the environment in the development, processing of materials such as marble, stone, copper, or the industrial revolution. This finding justifies the claim in literature that merging points between the two subjects is restricted to the contribution of history in the progress of science (Fauvel \& Maanen, 2005; Mason \& Vasquez-Abad, 2006).

Similarly, the number of units in religion that are linked to science is small, even though integration is stressed in the subjects' curriculum. These units address environmental issues and the need to respect the environment, nature, and ecosystems. This probably is congruent with the claims made by Barbour (2000) and Hanley et al (2013) that science and religion may work as supplements to each other.

In geography, however, the number of codes is sizebale. In the teachers' book, science is generally mentioned multiple times. There are several units referring to the landscape, environment, flora and fauna, earth, sun, ecosystems, and climate. This is compatible with research that found that the teaching of environmental topics are opportunities for the integration of science and geography (Lisowski, 2011; Drake \& Reid, 2018).

Finally, in politics, despite the fact that integration is considered to be important in the curriculum, the codes in the book were also limited. There were limited units that referred to science, mostly focusing on environmental issues and the importance of science in everyday life. The research findings seem to be justified in this case too (Lemke, 2001; Gresch \& Martens, 2019).

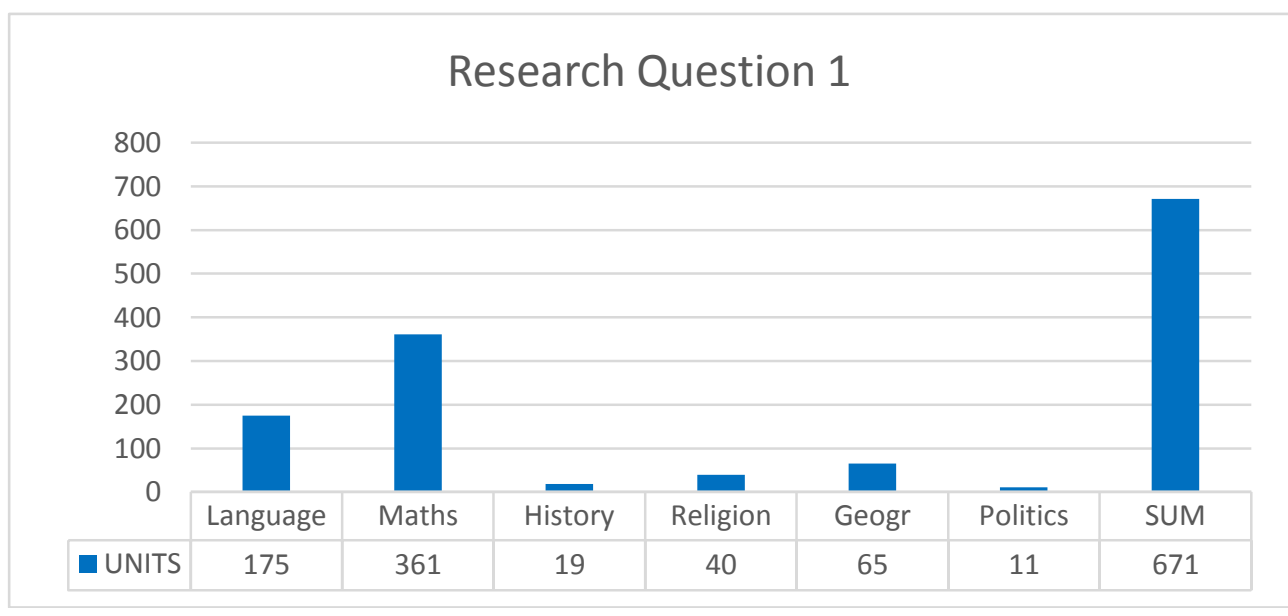

Graph 1. Codes around units relevant to science found in the teaching packages

As these findings show, the teaching packages include concepts that assist in cross-curricular science activities that are also promoted in the curricula. This compatibility sometimes may not exist in other contexts (Hodson, 2008). These concepts can either be parts in units and chapters that are in the teaching 
packages or suggestions and proposals from the curriculum that teachers can implement. Nevertheless, there are definitely subjects that have more common features with science, which have been mentioned in the literature. Such subjects are language (Akerson \& Flanigan, 2000), mathematics (Lonning \& DeFranco, 1997), and geography (Drake \& Reid, 2010). However, there others that are justifiably less connected, such as history (Mason \& Vasquez-Abad, 2006), religion (Barbour 2000), and politics (Lemke, 2010). Moreover, it seems that the teaching of topics, such as those on the environment, are considered as effective opportunities for integration with science since they actually help in connecting scientific knowledge with other disciplines and in their application (Lisowski, 2011; NGSS Lead States, 2013). Pang and Good (2000) along with Gresnigt (2018) claim that these conditions are beneficial for the involvement of actual applied teaching of scientific literacy.

\section{Research Question 2}

In the second research question, as shown in Graph 2, codes around activities have been found. In the language teaching package, however, there are only a few. More specifically, there are activities involving the environment ("What are the animals doing?", "What are the characteristics of the animals in the garden?"), the climate ("seasons", "snow in the island"), ecosystems ("walk in the mountains"), mixtures and solutions ("clean water", "baking cookies with olive oil"), item and materials ("how to construct an instrument"), and the light ("how is the rainbow created?"). Such activities are justified by research as being common tasks that combine language and science (Cervetti et al., 2007). In certain activities, such as the one with the rainbow, the linkage with science is direct. In others, where it is not, the teacher is responsible for appropriately designing integrating tasks if they are to be used as such (Davison et al., 1995). In any case, this might assist in the implementation of integration (Hodson, 2008).

The teaching package of mathematics included many codes. As with concepts, there were several activities involving length, volume, time, space, mass-weight, and measurement units. Aside from that, there were activities that had topics not relevant to science but with contexts that were. For example, there are activities around ratio that require children to find out how many oranges produce a certain amount of juice. These kinds of activities are commonly suggested to combine mathematics and science (Lonning \& DeFranco, 1997).

In history, unlike concepts, there are various activities that are linked to science. Various activities mainly related to mythology can be linked to animals and their characteristics. Other activities can be related to economic activities, developed in communities of the past, that are related to science. These include pottery, ecosystems, rivers, water system development, sailing, or even silkworm breeding. Moreover, there are a few activities that stress how science development influenced peoples' thinking and perception. This justifies the findings that the integration of science and history is common when teaching how the development of the former contributed to the development of regions (Fauvel \& Maanen, 2005; Mason \& Vasquez-Abad, 2006).

The codes in the teaching packages on religion are limited. Perhaps, the only activities in this subject that can be related to science are those that underline the 
necessity that humans generally respect the environment, which includes their own existence. There are also a few activities about topics such as illnesses, health and well-being. As with the concepts in the first research question, these activities show how the two subjects supplement each other (Barbour, 2000; Hanley et al., 2013).

The geography teaching packages have several activities that can be integrated with science. The environment of areas serves as a context as was seen with the concepts as well. Examples of such activities include the classification of valleys, rivers, ecosystems, linking altitude, or landscapes with jobs in specific areas, differentiating between weather and climate, or developing agricultural cooperation in an area. These activities can show how scientific knowledge links with the environment, economy, and society, which is common when integrating science and geography (Schaefer, 1953; Baerwald, 2010).

Lastly, in politics, there are only a few activities that are integrated with science. They are those that usually stress the need for active citizenship in dealing with challenges such as the environment, science ethics, or other topics as sound pollution. This is compatible with the research findings (Lemke, 2001; Gresch \& Martens, 2019).

In short, at the activities level, for some subjects, such as language, religion, and politics, a few can be used for integration with science. This shows incompatibility between the curricula and teaching packages. Research has justified similar conclusions (Hodson, 1992, 2008). This does not seem to be the case in mathematics, history, and geography, where the units and activities suggested seem to be alike. As with units, the environment as a topic seems to be promoted as opportunities for integration with science since it helps learners connect and apply their knowledge of science in real-life problems (NGSS Lead States, 2013). However, in all subjects, there seems to be room for further initiative for teachers to design and implement integrating projects. This is because in some activities, the connection with science may not be straightforward, but teachers can plan its integration by themselves (Davison et al., 1995).

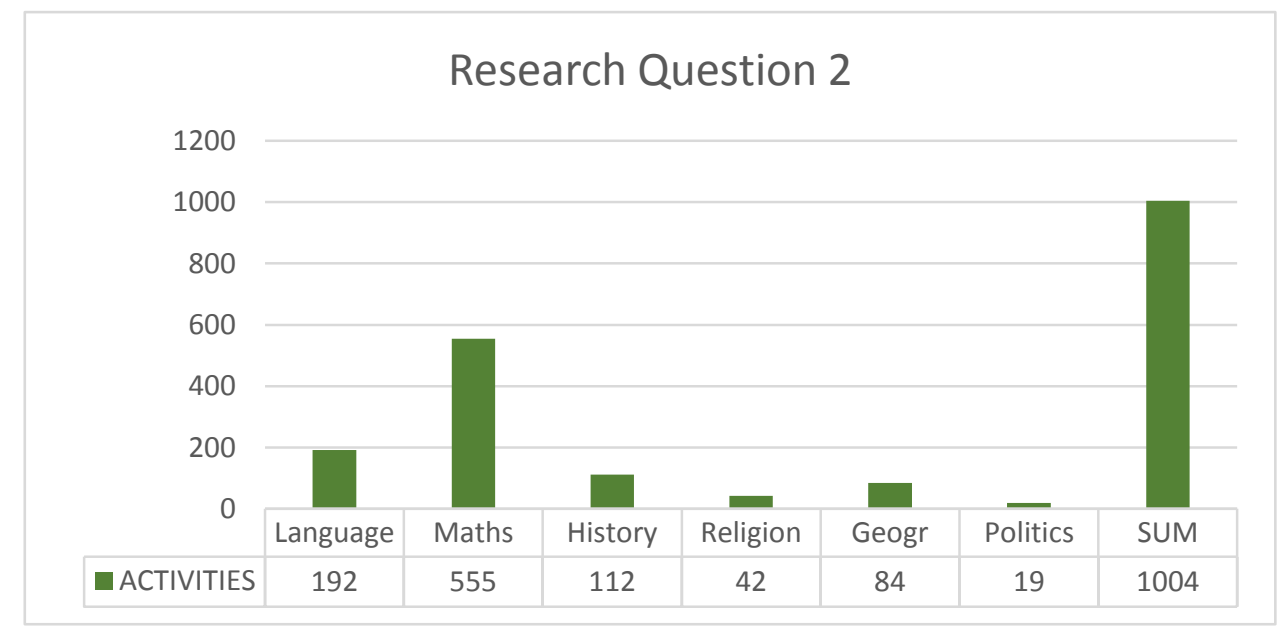

Graph 2. Codes around activities relevant to science found in the teaching packages 


\section{Research Question 3}

In the third research question, as seen in Graph 3, there are several nodes about practices and skills. More specifically, in the language curriculum as well as teachers' books, there are references to skills such as critical thinking, data collection, discourse as well as the claiming and disseminating of conclusions. These are implemented in the tasks in the units found in pupils' books and workbooks. Such activities are justified in the research as promoting the teaching of language and science in combination and thus, can be the core of integrating activities (Akerson \& Flanigan, 2000; Cervetti et al., 2007; Harlen \& Qualter, 2009; Jarvis, 2009).

The findings in mathematics are similar. Both the curricula and the teaching package had plenty of codes on skills relevant to science, such are observation, critical thinking, information search, problem solving, experimentation, hypothesizing, quantifying, discourse as well as the claiming and dissemination of findings. These skills are considered to be beneficial in integrating science and mathematics by research (Pang \& Good, 2000; French, 2004; Harlen \& Qualter, 2009; Jarvis, 2009).

In history, there are also such practices and competencies, such as critical thinking, observation, description, data or resource analysis, and conclusion statements, that are stressed in the curricula. The textbooks also contain activities promoting them, and science teaching can benefit from such tasks (Fauvel \& Maanen, 2005; Mason \& Vasquez-Abad, 2006; Harlen \& Qualter, 2009; Jarvis, 2009).

In religion there are practices and competencies common with science too. As pointed out in the curriculum and applied in the textbooks, while teaching about attitudes towards environment, there are tasks focused on observation, critical thinking, and discourse, which are common with science as well (Hanley et al., 2010; NGSS Lead States, 2013).

Science skills are even more apparent in the geography curriculum, which pays significant attention to skills such as observing, hypothesizing, and experimenting. Aside from that, the textbooks contain several relevant activities such as those that encourage pupils to comment and conclude based on maps and diagrams as well as calculate, estimate, and justify based on scientific ideas on topics concerning the weather and ecosystems. This justifies that geography as a subject is a good opportunity for learners to implement science into real-life contexts (Lisowski 2011; Drake \& Reid, 2018). 


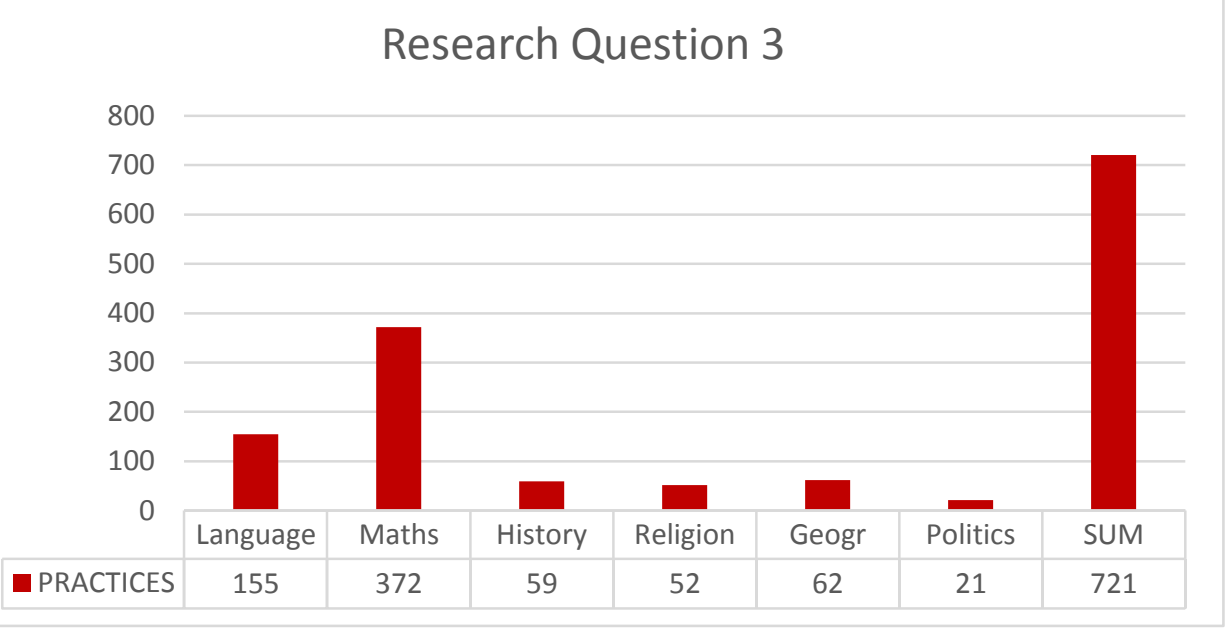

Graph3. Codes around practices relevant to science found in the teaching packages

Lastly, in politics, there are also skills relevant to science. The curriculum mentions the necessity of skills such as collaborating, observing, and thinking critically. Tasks in the textbooks in units, such as respect for environmental protection, motivate learners to use and develop such practices and can assist in the promotion of science literacy (Lemke, 2001; NGSS Lead States, 2013; Gresch \& Martens, 2019).

In short, at the level of practices, there are several activities for the integration of science with other subjects. The compatibility between curricula and teaching packages facilitates teachers to design and carry out these activities. It also assists in the promotion of teaching through science inquiry in science as well as in other subjects (Hodson, 1992, 2008; Harlen \& Qualter, 2009; Jarvis, 2009; Gresnigt, 2018; Trisdiono et al, 2019; Sirih et al, 2019).

\section{Conclusions}

This study aimed to identify potential for integrating science with other subjects in elementary school grades in Greece as they exist in teaching packages. Integrating can assist teachers' work as it promotes a holistic approach towards knowledge around certain topics. There have been plenty of suggestions for the integration of science with language and mathematics (Jacobs, 1989; French, 2004; Harlen \& Qualter, 2009; MINEDU, 2018). However, researchers and theorists have also highlighted the challenges in their implementation, which may be attributed to the incompatibility of teaching packages and curricula (Hodson, 1992; 2008). These challenges can be dealt with by using the assistance of an appropriately designed teaching package that supports integration (Harlen \& Qualter, 2009; MINEDU, 2018).

Unlike most projects around integrating science, which usually focus on specific other subjects individually, this study examines possibilities of integration with most subjects of elementary school in the Greek education context.

Integrating activities in different subjects can be implemented on three different levels. The first is at the level of concepts, which addresses units, chapters, and 
topics relevant to subjects. The second is at the level of activities, and the third is at the level of skills and practices (Davison et al., 1995).

Through a qualitative approach, this study analyzed curricula and teaching packages of subjects taught by mainstream elementary teachers in schools in Greece, aiming to identify concepts, activities and skills that can be relevant to science (Pang \& Good, 2000; Cohen et al., 2013). The findings indicated that there are opportunities in all three levels and that there is also adequate compatibility of the teaching packages and curricula. This is in favor of the implementation of science integration (Hargreaves, 1991; Loepp, 1999; Gresnigt, 2018) and the achieving of science literacy (OECD, 2017).

However, prior to generalization, it is necessary to stress the limitations of this study. The research focused on contemporary curricula and teaching packages of Greek elementary schools and more specifically, on curricula and teaching packages. It was also difficult to do a detailed comparison between the subjects as they are not all taught in the same grades and same sessions per week.

Further research could focus on other dimensions of this topic, such as the perceptions of educators, which could lead to significant conclusions thanks to the necessary "triangulation" (Cohen et al, 2013, p. 195).

\section{References}

Abd-El-Khalick, F., Bell, R. L., \& Lederman, N. G. (1998). The nature of science and instructional practice: Making the unnatural natural. Science Education, 82(4), 417-436.

Akerson, V. \& Flanigan, J. (2000). Preparing preservice teachers to use an interdisciplinary approach to science and language arts instruction. Journal of Science Teacher Education, 11(4), 345-362.

Akerson, V. L., \& Hanuscin, D. L. (2007). Teaching nature of science through inquiry: Results of a 3- year professional development program. Journal of Research in Science Teaching, 44(5), 653-680.

Banks, J., (1993). Multicultural Education: Developments Dimensions and Challenges. Phi Delta Kappan, 75(1), 22-28.

Barbour, I. G. (2000). When science meets religion: Enemies, strangers, or partners? London: SPCK.

Baerwald, T. J. (2010). Prospects for geography as an interdisciplinary discipline. Annals of the Association of American Geographers, 100(3), 493-501. https://doi.org/10.1080/00045608.2010.485443

Cervetti, G., Pearson, P. D., Barber, J., Hiebert, E., \& Bravo, M. (2007). Integrating literacy and science. In M. Pressley, A. K. Billman, K. Perry, K. Refitt \& J. Reynolds (Eds.), Shaping literacy achievement: The research we have, the research we need (pp. 157-174). New York: The Guilford Press.

Cohen, L., Manion, L., \& Morrison, K. (2013). Research methods in education (7th ed.). London: Routledge.

Davison, D. M., Miller, K. W., \& Metheny, D. L. (1995). What does integration of science and mathematics really mean? School Science and Mathematics, 95(5), 226-230.

Drake, S. M., \& Reid, J. L. (2018). Integrated curriculum as an effective way to teach 21st century capabilities. Asia Pacific Journal of Educational Research, 1(1), 31-50.

Elstad, E., Lejonberg, E., \& Christophersen, K.-A. (2019). Policy Mediated through Subject Matter Contexts: Antecedents of Subject-Bound Differences in Teachers' 
Perceptions of Collaboration across Subjects. International Journal of Learning, Teaching and Educational Research, 18(4), 1-16. https:// doi.org/10.26803/ijlter.18.4.1

Fauvel, J., \& Maanen, J. (2005). History in mathematics education. New York: Kluwer Academic Publishers.

French, L. (2004). Science as the center of a coherent, integrated, early childhood curriculum. Early Childhood Research Quarterly, 19, 138-149.

Gauld, C. F. (2005). Habits of mind, scholarship and decision making in science and religion. Science $\mathcal{E}$ Education, 14(3-5), 291-308. https://doi.org/10.1007/s11191004-1997-x

Gresch, H., \& Martens, M. (2019). Teleology as a tacit dimension of teaching and learning evolution: A sociological approach to classroom interaction in science education. Journal of Research in Science Teaching, 56(3), 243-269. https://doi.org/10.1002/tea.21518

Gresnigt, R. (2018). Integrated curricula: An approach to strengthen science $\mathcal{E}$ technology in primary education. Eindhoven: Technische Universiteit Eindhoven.

Hanley, P. M., Bennett, J. M., \& Ratcliffe, M. (2013). The inter-relationship of science and religion: A typology of engagement. International Journal of Science Education, 36(7), 1210-1229.

Hanuscin, D. L., Lee, M. H., \& Akerson, V. L. (2011). Elementary teachers' pedagogical content knowledge for teaching the nature of science. Science Education, 95(1), 145-167.

Hargreaves, D. H. (1991). Coherence and manageability: Reflections on the national curriculum and cross curricular provision. The Curriculum Journal, 2(1), 33-41. https://doi.org/10.1080/0958517910020104

Harlen, W., \& Qualter, A. (2009). The teaching of science in primary schools (5th ed.). London: Routledge.

Hodson, D. (1992). In search of a meaningful relationship: An exploration of some issues relating to integration in science and science education. International Journal of Science Education, 14(5), 541-562.

Hodson, D. (2008). Towards scientific literacy: A teachers' guide to the history, philosophy and sociology of science. Rotterdam: Sense Publishers.

Hudson, P. F., \& Hinman, S. E. (2017). The integration of geography in a curriculum focused to internationalization: An interdisciplinary liberal arts perspective from the Netherlands. Journal of Geography in Higher Education, 41(4), 549-561. https://doi.org/10.1080/03098265.2017.1337089

Jacobs, H. H. (1989). Interdisciplinary curriculum: Design and implementation. Alexandria, VA: Association for Supervision and Curriculum Development.

Jarvis, T. (2009). Promoting creative cross-curricular work through an in-service programme. School Science Review, 90(3), 39-46. Retrieved from https://www.ase.org.uk/journals/school-science-review/2009/03/332/

Jegede, O. J., \& Aikenhead, G. S. (1999). Transcending cultural borders: Implications for science teaching. Research in Science \& Technological Education, 17(1), 45-66.

Lemke, J. L. (2001). Articulating communities: Sociocultural perspectives on science education. Journal of Research in Science Teaching, 38(3), 296-316.

Loepp, F. L. (1999). Models of curriculum integration. The Journal of Technology Studies, 25(2), 21-25.

Lonning, R. A., \& DeFranco, T. C. (1997). Integration of science and mathematics: A theoretical model. School Science and Mathematics, 97(4), 212-215. 
Lisowski, A. (2011). Geography and social sciences in transdisciplinary science. Miscellanea Geographica - Regional Studies on Development, 15(1). https://doi.org/10.2478/v10288-012-0001-x

Masson, S., \& Vázquez-Abad, J. (2006). Integrating history of science in science education through historical microworlds to promote conceptual change. Journal of Science Education and Technology, 15(3-4), 257-268. https://doi.org/10.1007/s10956-0069012-8

MINEDU. (2018). Interactive teaching packages and school textbooks. Retrieved from http://ebooks.edu.gr/new/allmaterial.php

NGSS Lead States. (2013). Next generation science standards: For states, by states. Washington, DC: The National Academies Press.

OECD. (2017). PISA 2015 assessment and analytical framework: Science, reading, mathematic, financial literacy and collaborative problem solving. Paris: PISA, OECD Publishing. https://doi.org/10.1787/9789264281820-en.

Pang, J., \& Good, R. (2000). A review of the integration of science and mathematics: Implications for further research. School Science and Mathematics, 100(2), 73-82.

Schaefer, F. K. (1953). Exceptionalism in geography: A methodological examination. Annals of the Association of American Geographers, 43(3), 226-249. https:// doi.org/10.1080/00045605309352114

Sirih, M., Ibrahim, N., \& Priyono. (2019). The Effect of Learning Models and Spatial Intelligences to Biology Learning Outcomes by Controlling the Initial Knowledge. International Journal of Learning, Teaching and Educational Research, 18(6), 20-38. https://doi.org/10.26803/ijlter.18.6.2

Trisdiono, H., Siswandari, S., Suryani, N., \& Joyoatmojo, S. (2019). Multidisciplinary Integrated Project-based Learning to Improve Critical Thinking Skills and Collaboration. International Journal of Learning, Teaching and Educational Research, 18(1), 16-30. https://doi.org/10.26803/ijlter.18.1.2 